\title{
Frovatriptan for the Acute Treatment of Migraine
}

\author{
Peer Tfelt-Hansen
}

Senior Consultant, Department of Neurology and Danish Headache Centre, Glostrup Hospital, University of Copenhagen

\begin{abstract}
Frovatriptan $2.5 \mathrm{mg}$ has been investigated for the treatment of moderate or severe migraine attacks in six placebo-controlled, randomised controlled trials (RCTS). The mean headache relief (a decrease from moderate or severe to none or mild) was $43 \%$ after frovatriptan and $24 \%$ after placebo. The mean therapeutic gain (active minus placebo) was $19 \%$ (95\% confidence interval 16-22 \%). In one large comparative RCT, sumatriptan $100 \mathrm{mg}$ was superior to frovatriptan $2.5 \mathrm{mg}$ for headache relief at two hours (47 versus $37 \%$ ). In three cross-over RCTs in which the patients treated migraine attacks as early as possible, frovatriptan 2.5 mg was quite similar to zolmitriptan $2.5 \mathrm{mg}$, rizatriptan $10 \mathrm{mg}$ and almotriptan $12.5 \mathrm{mg}$ for preference - the primary efficacy measure. It is concluded that frovatriptan is not the triptan of first choice in established moderate to severe migraine attacks (based on systematic reviews and one comparative RCT). However, if the patients can treat their migraine attacks at the start of an attack (and are not triptan-resistant), then frovatriptan is a reasonable treatment choice among the triptans.
\end{abstract}

\section{Keywords}

Frovatriptan, sumatriptan, zolmitriptan, rizatriptan, almotriptan, randomised controlled trials, therapeutic gain

Disclosure: The author has no conflicts of interest to declare.

Received: 31 March 2011 Accepted: 4 July 2011 Citation: European Neurological Review, 2011;6(4):262-4 DOI:10.17925/ENR.2011.06.04.262

Correspondence: Peer Tfelt-Hansen, Department of Neurology, Danish Headache Center, Glostrup Hospital, University of Copenhagen, 2000, Glostrup, Denmark.

E: ptha@glo.regionh.dk

Frovatriptan is a $5 \mathrm{HT} 1 \mathrm{~B} / 1 \mathrm{D}$ receptor agonist ${ }^{1}$ and has been developed as a triptan with a long terminal half-life $\left(\mathrm{t}_{1 / 2}\right) .{ }^{2}$ Recurrence, the relapse of migraine headache after an initial successful treatment, is a major problem in migraine treatment. ${ }^{1}$ After treatment with other triptans, recurrence occurs in 30-40 \% of treated attacks. ${ }^{1}$ The triptans, apart from frovatriptan, have a relatively short $t_{1 / 2}$ of two to five hours. ${ }^{1.3}$ Frovatriptan has a $t_{1 / 2}$ of 26 hours and this may reduce the likelihood of early migraine recurrence. ${ }^{2}$

In this article, I review the use of frovatriptan in acute migraine treatment. The long $t_{1 / 2}$ of frovatriptan suggests a long duration of action of the drug and frovatriptan has therefore been investigated for prophylaxis of menstrual-associated migraine. For a review of randomised controlled trials (RCTs) with frovatriptan used for the prevention of menstrual-associated migraine - see MacGregor, $2010 .{ }^{4}$

\section{Pharmacokinetics of Frovatriptan}

Frovatriptan has an oral bioavailability of $30 \% .^{1-3}$ The time to maximum plasma concentration is two to three hours but $60-70 \%$ of the maximum concentration is reached after one hour. ${ }^{2}$ The terminal $t_{1 / 2}$ is 26 hours. $^{2}$

\section{Efficacy and Tolerability of Frovatriptan in Acute Migraine Treatment}

Frovatriptan has been investigated in both placebo-controlled RCTs and comparative RCTs versus other triptans. There are no trials investigating frovatriptan versus aspirin (with or without metoclopramide) or other non-steroidal anti-inflammatory drugs. The effects of frovatriptan have also been evaluated in a meta-analysis ${ }^{5}$ and in systematic reviews. ${ }^{1,6}$
Frovatriptan has been investigated in six placebo-controlled RCTs, mainly in white people ${ }^{-1,6,7}$ the results of one of these trials have never been fully published. ${ }^{7.8}$ In addition, there has been one Korean placebo-controlled RCT. ${ }^{9}$ In the six RCTs the mean therapeutic gain (active minus placebo) for frovatriptan $2.5 \mathrm{mg}$ was $19 \%$ (95\% confidence interval [Cl] 16-22 \%) after two hours (based on 2,174 patients treated with frovatriptan [headache relief in $43 \%$ ] and 1,299 patients treated with placebo [headache relief in $24 \%$ ] $)^{1,7}$ (see Figure 1). Similarly, in the Korean patients the headache relief after two hours was $53 \%$ in patients treated with frovatriptan and $34 \%$ for those receiving placebo (therapeutic gain $=19 \%$ ). ${ }^{9}$ Recurrence rates of 7-25\% (mean $17 \%$ ) were reported for frovatriptan $2.5 \mathrm{mg}$.

In one comparative parallel group, placebo-controlled RCT, frovatriptan $2.5 \mathrm{mg}$ was inferior to sumatriptan $100 \mathrm{mg}$ but both drugs were superior to placebo. ${ }^{7.8}$ Sumatriptan was superior to frovatriptan for headache relief at two hours (47 versus $37 \%$ ) and pain free after two hours (18 versus $9 \%$ ). The recurrence rates were similar for frovatriptan and sumatriptan (25 versus $31 \%$ ) (see Table 1). It should be noted that this was a very large RCT with a total of 1,196 migraine attacks treated.?

In three smaller Italian RCTs, but with the more powerful cross-over design, frovatriptan $2.5 \mathrm{mg}$ was compared with zolmitriptan $2.55 \mathrm{mg}_{,}{ }^{10}$ rizatriptan $10 \mathrm{mg}^{11}$ and almotriptan $12.5 \mathrm{mg}^{12}$ (see Table 2). In each case, preference rating for the two triptans, the primary efficacy parameter, was the same, as were pain free and pain relief after two hours. In contrast, recurrences were lower for frovatriptan 
Table 1: Effects of Frovatriptan, Sumatriptan and Placebo in One Large Randomised Controlled Trial $(n=1,196)^{7,8}$

\begin{tabular}{|c|c|c|c|}
\hline \multirow[t]{2}{*}{ Efficacy Measure } & \multicolumn{3}{|l|}{ Treatment } \\
\hline & Frovatriptan $2.5 \mathrm{mg}(\mathrm{n}=475)$ & Sumatriptan $100 \mathrm{mg}(\mathrm{n}=479)$ & Placebo $(n=242)$ \\
\hline Headache relief at two hours (\%) & $37^{\star}$ & $47 *, \star *$ & 23 \\
\hline Headache recurrence at 4-24 hours (\%) & 25 & 31 & 31 \\
\hline Pain free at two hours (\%) & $9 *$ & $18 *, * *$ & 3 \\
\hline
\end{tabular}

* $p \leq 0.01$ versus placebo; **p<0.001 versus frovatriptan.

Table 2: Results of Three Cross-over Randomised Controlled Trials Comparing Frovatriptan with Zolmitriptan, Rizatriptan and Almotriptan

\begin{tabular}{|c|c|c|c|c|c|}
\hline Drug & $\begin{array}{l}\text { Preference on } \\
\text { Five-point Scale }\end{array}$ & $\begin{array}{l}\text { Pain Free at } \\
\text { Two Hours (\%) }\end{array}$ & $\begin{array}{l}\text { Headache Relief at } \\
\text { Two Hours (\%) }\end{array}$ & Recurrence (\%) & $\begin{array}{l}\text { Sustained Pain Free } \\
\text { at } 2-48 \text { hours (\%) }\end{array}$ \\
\hline Frovatriptan & 2.9 & 26 & 57 & 21 & 18 \\
\hline Zolmitriptan & 3.0 & 31 & 58 & 24 & 22 \\
\hline Frovatriptan & 2.9 & 33 & 55 & 21 & 26 \\
\hline Rizatriptan & 3.2 & 39 & 62 & 43 & 22 \\
\hline Frovatriptan & 3.1 & 30 & 54 & 30 & 21 \\
\hline Almotriptan & 3.4 & 32 & 56 & 44 & 18 \\
\hline
\end{tabular}

Preference, pain free at two hours, headache relief (a decrease in headache from moderate or severe to none or mild) at two hours, recurrence rates and sustained pain-free response (2-48 hours) in three cross-over randomised controlled trials comparing frovatriptan $2.5 \mathrm{mg}$ with zolmitriptan $2.5 \mathrm{mg}$ (Bartolini et al., $\left.2011^{12}\right)$, rizatriptan $10 \mathrm{mg}\left(\right.$ Savi et al., $\left.2011^{11}\right)$ and almotriptan $12.5 \mathrm{mg}$ (Tullo et al., $2010^{10}$ ).

$\left(21^{11}\right.$ and $\left.30 \%{ }^{12}\right)$ than for rizatriptan $(43 \%)^{11}$ and almotriptan $(44 \%){ }^{12}$ In the RCT of frovatriptan versus zolmitriptan, the recurrence rates were 21 and $24 \%$, respectively. ${ }^{10}$ However, the relevant efficacy parameter is not recurrence rate but sustained pain free for 48 hours. $^{13}$ This parameter was quite similar for frovatriptan and the three other triptans (21 versus $18 \%$; 26 versus $22 \%$; 18 versus $22 \%$ ) (see Table 2).

In five RCTs frovatriptan caused more adverse events (AES) than placebo (relative risk 1.31; $95 \% \mathrm{Cl} 1.07-1.62$ ). ${ }^{6}$ In one RCT frovatriptan $2.5 \mathrm{mg}$ caused fewer AEs (36 \%) than sumatriptan $100 \mathrm{mg}$ (45 \%). ${ }^{7.14}$ In two comparative RCTs ${ }^{11,12}$ frovatriptan caused a similar number of AES as rizatriptan and almotriptan. In one RCT frovatriptan caused fewer drug-related AES (3\%) than zolmitriptan $(10 \%) .^{10}$

\section{Comments}

For frovatriptan, there is apparently a discrepancy between the results of a meta-analysis/systematic reviews ${ }^{1,5,6}$ and the results of the large comparative $\mathrm{RCT}^{7}$, with sumatriptan and the three cross-over RCTs comparing frovatriptan with zolmitriptan, ${ }^{10}$ rizatriptan ${ }^{11}$ and almotriptan. ${ }^{12}$ The results for therapeutic gain for headache relief from one systematic review ${ }^{1.7}$ are shown in Table 3 for frovatriptan $2.5 \mathrm{mg}$, zolmitriptan $2.5 \mathrm{mg}$, rizatriptan $10 \mathrm{mg}$, almotriptan $12.5 \mathrm{mg}$ and sumatriptan $100 \mathrm{mg}$. For mean headache relief, frovatriptan $2.5 \mathrm{mg}$ (43\%) was inferior to zolmitriptan $2.5 \mathrm{mg}$ (63\%), rizatriptan $10 \mathrm{mg}$ (69\%), almotriptan $12.5 \mathrm{mg}$ (61\%) and sumatriptan $100 \mathrm{mg}$ (61\%). However, in a meta-analytic comparison the relevant parameter is therapeutic gain (active minus placebo) and, as shown in Table 3, this was lower for frovatriptan than for sumatriptan, zolmitriptan and rizatriptan whereas the $95 \% \mathrm{Cls}$ for frovatriptan and almotriptan were overlapping.

It is noteworthy that headache relief at two hours for frovatriptan was higher in the three cross-over RCTs (57, 55, 54 \%) (see Table 2) than headache relief in the systematic reviews (43\%). ${ }^{1,6}$ This suggests that the migraine population investigated in the three cross-over RCTs had less severe headaches. ${ }^{10-12}$ Furthermore, whereas patients in
Figure 1: Mean Headache Relief After Two Hours of taking Frovatriptan $2.5 \mathrm{mg}$ or Placebo in Patients suffering from Migraine Attacks

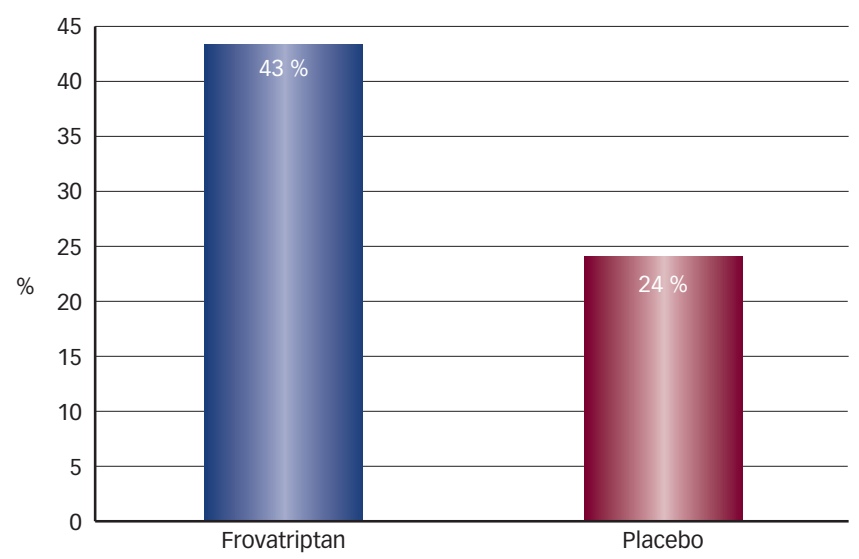

Results of a systematic review (Tfelt-Hansen, 2008; Hutchison et al., 2007).

Table 3: Therapeutic Gains from Different Drugs against Placebo for Headache Relief - Results from One Systematic Review

\begin{tabular}{|c|c|c|c|}
\hline Drug and Dose & Patients (n) & $\begin{array}{l}\text { Mean Headache } \\
\text { Relief (\%) }\end{array}$ & $\begin{array}{l}\text { Mean Therapeutic } \\
\text { Gain ( } 95 \% \\
\text { confidence interval) }\end{array}$ \\
\hline Frovatriptan $2.5 \mathrm{mg}$ & 2,174 & 43 & $19(16-22)$ \\
\hline Placebo & 1,299 & 24 & \\
\hline Zolmitriptan $2.5 \mathrm{mg}$ & 1,583 & 63 & $34(30-37)$ \\
\hline Placebo & 795 & 29 & \\
\hline Rizatriptan 10 mg & 2,253 & 69 & $36(32-39)$ \\
\hline Placebo & 982 & 33 & \\
\hline Almotriptan $12.5 \mathrm{mg}$ & 721 & 61 & $27(20-33)$ \\
\hline Placebo & 335 & 35 & \\
\hline Sumatriptan 100 mg & 3,874 & 61 & $33(31-35)$ \\
\hline Placebo & 2,151 & 28 & \\
\hline
\end{tabular}

Total number of patients, mean headache relief (a decrease from moderate or severe headache to none or mild) and $95 \%$ confidence intervals for headache relief in one systematic review (Saxena et al., 2006'; see also Tfelt-Hansen, 2008'). 
the placebo-controlled RCTs ${ }^{1,6,7}$ had moderate or severe headache at the time of receiving the test medication, the instruction given to patients in the cross-over RCTs was different - they should take one dose of study medication as early as possible after the onset of a migraine attack. ${ }^{10-12}$ The actual severity of treated attacks is not reported in these articles, ${ }^{10-12}$ which is a rather peculiar omission when reporting on a RCT in acute migraine treatment. Another contributing factor could be exclusion of patients with previously demonstrated inadequate response to at least two triptans. ${ }^{10-12}$
In conclusion, for moderate and severe headache, frovatriptan is a 'low-efficacy' triptan (therapeutic gain is only 19 versus $27-36 \%$ for other triptans; see Table 3). Frovatriptan is thus not the triptan of first choice for established migraine attacks (e.g. morning migraine). However, if patients with migraine are able to treat their attacks very early, and have not demonstrated inadequate response to other triptans, then frovatriptan is most likely a good alternative to other triptans. Finally, the relative efficacy of frovatriptan versus aspirin (with or without metoclopramide) remains to be investigated.
1. Saxena PR, Tfelt-Hansen P, Triptans, 5HT1B/1D agonists in the acute treatment of migraine. In: Olesen J, Goadsby PJ, Ramadan NM, et al. (eds), The Headaches, 3rd ed., Philadelphia: Lippincott Williams \& Wilkins, 2006;469-503.

2. Buchan P, Keywood C, Wade A, Ward C, Clinica pharmacokinetics of frovatriptan, Headache, 2002;42(Suppl. 2):S54-62.

3. Tfelt-Hansen P, De Vries P, Saxena PR, Triptans in migraine. A comparative review of pharmacology, pharmacokinetics and efficacy, Drugs, 2000;60:1259-87.

4. MacGregor EA, Prevention and treatment of migraine, Drugs, 2010:70:1799-818

5. Ferrari MD, Roon KI, Lipton RB, Goadsby PJ, Oral triptan (serotonin 5-HT (1B/1D) agonists) in the acute migraine treatment: a meta-analysis of 53 trials, Lancet, 2001;358:1668-75.
6. Poolsup $N$, Leesangaluk $V$, Jittangtrong $V$, et al., Efficacy and tolerability of frovatriptan in acute migraine treatment: systematic review of randomized controlled trials, I Clin Pharm Ther, 2005;30:521-32.

7. Tfelt-Hansen P, Frovatriptan and data publication, Headache, 2008;48:1382-3

8. Hutchison J, Pfaffenrath V, Geraud G, A randomized, placebo-controlled, parallel group trial of frovatriptan and sumatriptan for a single acute migraine attack, Eur I Neurol , 2007;14(Suppl. 1):144.

9. Moon HS, Chu MK, Park JW, et al., Frovatriptan is effective and well tolerated in Korean migraineurs: double-blind, randomized, placebo-controlled trial I Clin Neurol, 2010; 6:27-32.

10. Tullo V, Allais G, Ferrari MD, et al., Frovatriptan versus zolmitriptan for the acute treatment of migraine: a double-blind, randomized, multicenter, Italian study ،
Neurol Sci, 2010:31(Suppl. 1):S51-4.

11. Savi L, Omboni $\mathrm{S}$, Lisotto $\mathrm{C}$, et al., A double-blind, randomized, multicenter, Italian study of frovatriptan versus izatriptan for the acute treatment of migraine, J Headache Pain, 2011;12:219-26.

12. Bartolini M, Giamberardino MA, Lisotto C, et al., A double-blind, randomized, multicenter, Italian study of frovatriptan versus almotriptan for the acute treatment of migraine, J Headache Pain, 2011;12:361-8.

13. Tfelt-Hansen $P$, Block $G$, Dahlöf $C$, et al., International Headache Society Clinical Trial Subcommittee, Guidelines Headache Society Clinical Trial Subcommittee, Guidelines cer con Cephalalgia, 2000;20:765-86.

14. Geraud G, Spierings EL, Keywood C, Tolerability and safety of frovatriptan with short- and long-term use for treatment of migraine and in comparison with sumatriptan, Headache, 2002;47(Suppl. 2):S93-9. 